\title{
Л.С. Гринкевич
}

\section{«НАЛОГОВЫЙ МАНЁВР», ДЕОФШОРИЗАЦИЯ ЭКОНОМИКИ И ДРУГИЕ НАПРАВЛЕНИЯ СОВРЕМЕННОЙ НАЛОГОВОЙ ПОЛИТИКИ РОССИИ}

\begin{abstract}
Формирование налоговой политики Российской Федерации проводилось в условиях надвигающегося финансового и внешнеэкономического кризиса, что затрудняло выбор механизмов её реализации. В статье систематизируются выбранные Правительством РФ и согласованные с общественностью направления налоговой политики страны и инструменты её реализации. Даётся оченка преемственности новых инструментов налоговой политики, их иелесообразности и значимости для государства $и$ бизнеса. Предлагаются дальнейтие шаги по усовершенствованию механизмов налоговой политики и повышению её социильно-экономической результативности.

Ключевые слова: налоговая политика, налоговый маневр, деофиоризация экономики, совершенствование налогового администрирования.
\end{abstract}

В условиях надвигающегося финансово-экономического кризиса перед Правительством РФ стоит очень тяжелая в решении задача - как скорректировать механизмы налоговой политики страны на 2015 и последующие годы? С одной стороны, требуется увеличить доходы бюджетной системы РФ (или хотя бы компенсировать выпадающие нефтегазовые поступления), а с другой - любое незначительное увеличение налоговой нагрузки может вызвать резкую негативную реакцию бизнеса, спровоцировать его свертывание и вывод капиталов за рубеж.

Итак, что планировалось сделать.

1. Предлагалось повысить основную ставку по налогу на добавленную стоимость (НДС) с 18 до 20\%. Дополнительные 2\% НДС, вероятно, дали бы существенную прибавку бюджетных поступлений, однако однозначно бы вызвали прирост стоимости продукции, работ, услуг по всей цепочке продвижения товаров и одновременно ухудшили бы финансовое положение организаций промышленного типа, создающих реальную добавленную стоимость, снизили платежеспособность контрагентов.

При этом прирост поступлений по данному налогу остается под сомнением. Так, по оценке В.Г. Панскова, наполнение доходной части федерального бюджета РФ по НДС в настоящее время составляет всего 6\%, а ранее оно составляло 17\%. При этом каждый недополученный процент по НДС - это 350 млрд руб. И основная причина такого снижения - использование незаконных «зачетных» схем [1].

2. Рассматривалось введение регионального налога с продаж в размере от 3 до 5\%. Это, по-мнению правительства, позволило бы финансово укрепить субъекты РФ, не затронув привычной схемы межбюджетного распределения налоговых доходов. 
Отметим, что использование двух налогов - одновременно НДС и налога с продаж - нонсенс для налоговой системы. Используется или один, или другой налог. В качестве единственной страны, применяющей и НДС и налог с продаж, можно назвать Канаду. С позиции функционирования экономики налог с продаж более благоприятен, чем НДС, он характеризует её результативность, так как чем больше товаров покупается и продаётся, чем выше платёжеспособный спрос, тем больше поступлений по налогу с продаж. Введение налога с продаж вместо НДС - такой вариант приемлем, и ранее неоднократно обсуждалась целесообразность такой замены, а дополнительный налог с продаж - это и инфляционный всплеск, и усиление дифференциации регионов и населения из-за существенно различающихся структуры и объёмов потребления.

3. Предлагалось повышение налога на доходы физических лиц (НДФЛ) до $15 \%$. О том, что НДФЛ не выполняет социально-регулирующей функции, каковы должны быть направления его реформирования, уже сказано неоднократно (см., например, [2]).

Учитывая, что основные поступления по НДФЛ дает бюджетная сфера, честно отражающая размеры оплаты труда, прирост доходов бюджетной системы был бы обеспечен. При этом мы придерживаемся позиции, что последовательность реформирования НДФЛ должна изначально основываться на выводе всех форм оплаты труда из «тени», а лишь потом можно реализовывать тот или иной вариант прогрессивного налогообложения. Так же интересным считаем альтернативное предложение о незамедлительном введении повышенного налога на сверхдоходы - дивиденды, доходы по ценным бумагам, от управления имуществом.

4. Предлагалась отмена регрессивной шкалы налогообложения по страховым взносам в Фонд обязательного медицинского страхования, повышение предельных размеров налоговой базы для начисления страховых взносов по максимальной ставке и её дифференциация для Пенсионного фонда РФ и Фонда социального страхования РФ.

Отметим, что повышение предельных размеров налоговой базы для начисления страховых взносов производится ежегодно, а вот дифференциация предельного лимита и его отмена в Фонд обязательного медицинского страхования вводится впервые и преследует цели увеличения поступлений в соответствующие внебюджетные фонды. Необходимостью сбалансировать пенсионную систему объясняется и введение дополнительных страховых тарифов в Пенсионный фонд с 2013 г. для лиц, занятых во вредных и тяжелых условиях труда и имеющих право досрочного выхода на пенсию [3].

Также традиционно предлагалось ввести дополнительные меры поддержки малого бизнеса, стимулировать инвестиции на отдаленных территориях и в отдельных отраслях (экспортно-ориентированных, социально значимых), продолжить работу по совершенствованию налогообложения земли и имущества физических и юридических лиц и др.

В результате был принят компромиссный, на наш взгляд, вариант, не ухудшающий условия функционирования среднего и малого бизнеса, обеспечивающий начало работы по регулированию уровня социальноэкономического расслоения общества и поддерживающий общее направле- 
ние модернизации российской налоговой системы, заложенное в предыдущие годы.

Рассмотрим основные приоритеты российской налоговой политики на 2015-2017 гг.

Важнейшим направлением налоговой политики страны остается обеспечение бюджетной устойчивости и сбалансированности бюджетной системы. В целях привлечения дополнительных доходов в бюджетную систему РФ альтернативой введения налога с продаж и увеличения ставки по НДС стало принятие комплекса поправок в Налоговый кодекс, получившего название «налоговый манёвр» [4]. Основой налогового маневра стало сокращение вывозных таможенных пошлин на нефть и нефтепродукты (в 1,7 раза за три года на нефть, в 1,7-5 раз на нефтепродукты в зависимости от видов нефтепродуктов с одновременным повышением ставок налога на добычу полезных ископаемых (НДПИ) - на нефть в 1,7 раза и газовый конденсат в 6,5 раза). При этом в целях предотвращения повышения цен на нефтепродукты и топливо внутри страны вводится поэтапное сокращение ставок акциза на нефтепродукты в 2,2 раза в течение трех лет, а также предоставление налогового вычета из сумм акциза при получении (приобретении в собственность) отдельных нефтепродуктов (бензина, авиационного керосина и др.).

Основными составляющими налоговой нагрузки в нефтяной отрасли являются НДПИ и экспортная пошлина, если компания экспортирует и не ограничивается внутренним рынком. В условиях резкого снижения курса рубля по отношению к основным валютам при одновременном снижении стоимости нефти следует пересчитать ожидаемые бюджетные поступления и налоговую нагрузку компаний за счет корректировки таможенной пошлины и размеров НДПИ. В таких условиях сомнительно, что большой налоговый манёвр в нефтяной отрасли простимулирует активизацию разработки новых месторождений и более эффективное использование действующих.

Кроме того, налоговый маневр включает:

- дополнение перечня подакцизных товаров (включение в перечень бензола, параксилола или ортоксилола, а также авиационного керосина и природного газа);

- увеличение налоговой ставки по налогу на прибыль с 9 до 13\% по доходам российских организаций в виде дивидендов;

- увеличение ставки НДФЛ в отношении доходов от долевого участия в деятельности организаций, полученных в виде дивидендов физическими лицами-резидентами РФ, с 9 до 13\%;

- индексацию ставок водного налога на установленные коэффициенты, а также увеличение ставок налога при изъятии ресурсов для водоснабжения населения.

Вторым приоритетным и последовательно реализуемым направлением налоговой политики РФ является борьба с массовым вывозом капиталов за рубеж и выведением налоговой базы из-под налогообложения в РФ.

Данное направление включает: совершенствование налогообложения иностранных компаний, действующих на территории России; изменение законодательства в сфере налогообложения процентов и дивидендов, получаемых от иностранных компаний; улучшение законодательства и практики ра- 
боты с трансфертным законодательством, совершенствование правил о «недостаточной капитализации» ст. 269 НК РФ; создание механизма налогообложения прибыли контролируемых иностранных компаний; введение мер противодействия по уклонению от уплаты налогов и сокрытию бенефициарных собственников; активное международное сотрудничество и «подключение» к проектам по противодействию снижению налоговой базы и перенесению доходов.

Так, с 1 января 2012 г. на основании принятия Федерального закона № 227-Ф3 [5] в РФ действует новый механизм контроля цен по сделкам между взаимозависимыми лицами, организациями, входящими в состав объединений и корпораций, и прочими субъектами, преследующими цель занижения налоговой базы по НДС, НДПИ, налогу на прибыль и НДФЛ.

Отметим, что модернизированный подход к организации контроля цен по сделкам существенно приближен к практике деятельности развитых зарубежных стран (Руководству ОЭСР): изменился состав взаимозависимых лиц, использованы новые критерии отнесения сделок к контролируемым, усовершенствованы методики доказательства соответствия применяемой цены рыночным условиям, изменилась последовательность контрольных мероприятий, введены новые контрольные органы: Управление трансфертного ценообразования и международного сотрудничества и Межрегиональная инспекция ФНС России по ценообразованию для целей налогообложения, формируются системные базы данных (СПАРК, AMADEUS, ORBIS).

Отличительной особенностью нового порядка контроля цен по сделкам является его превентивный характер и перенос ответственности на налогоплательщиков. Это означает, что при наличии у организации сделок, приравненных к контролируемым, они обязаны сами формировать доказательную базу и определять размер отклонений цен по сделкам от рыночных цен. Кроме того, налогоплательщики обязаны представлять в налоговые органы особый комплект документации - «уведомления о контролируемых сделках», содержащий подробную информацию о характере производственнофинансовой деятельности налогоплательщика, его партнерах, о контролируемых сделках и реализуемой методике подтверждения фактической цены проведенной сделки как рыночной [6]. Дальнейшая работа направлена на обеспечение соответствия результатов действия правил о трансфертном ценообразовании международным стандартам.

В число налоговых мер по деофшоризации экономики России входит принятие закона о контролируемых иностранных компаниях [7]. Закон предусматривает налогообложение нераспределенной прибыли иностранной компании, которая контролируется организациями или физическими лицами - налоговыми резидентами РФ - соответственно налогом на прибыль организаций или налогом на доходы физических лиц в соответствии с правилами российского налогового законодательства. Определено, кто и при каких условиях будет признаваться контролируемыми иностранными компаниями и контролирующими лицами, предусмотрено обязательное уведомление налогоплательщиками о своем участии в иностранных и российских организациях и иностранных структурах. Правительство считает, что введение данной 
меры будет стимулировать возврат бизнеса и его доходов под юрисдикцию России.

Отдельным направлением противодействия уклонению от налогообложения и получению необоснованной налоговой выгоды посредством использования низконалоговых юрисдикций и двусторонних договоров об избежании двойного налогообложения при выплате дивидендов, процентов, роялти является борьба с сокрытием бенефициарных собственников.

В соответствии с Национальным планом по противодействию уклонению от уплаты налогов и сокрытию бенефициарных собственников планируется:

- введение обязанности юридических лиц по формированию и ведению реестра бенефициарных собственников с обеспечением к нему доступа со стороны правоохранительных, налоговых и других компетентных органов;

- совершенствование механизмов информационного обмена между компетентными органами как на национальном, так и на международном уровне [8].

В качестве дополнительных обеспечительных мер также планируется введение запрета на предоставление любых форм государственной поддержки компаниям, использующим офшорные структуры, а также запрета на заключение с ними государственного контракта.

К числу мер по противодействию сокрытия доходов также относится совершенствование правил «тонкой капитализации» - это скрытое перераспределение дивидендов под видом процентных займов: помимо выявления и идентификации данных схем, принято решение, что если задолженность организации в три раза и более превышает уставной капитал, налоговые органы переквалифицируют выплаты в дивиденды.

На международном уровне Российская Федерация ратифицировала Конвенцию о взаимной административной помощи по налоговым делам (её подписали уже 99 стран), которая дает налоговым органам серьёзные рычаги по деофшоризации экономики, в том числе проведение совместных проверок по налогам; возможность взыскания налоговой задолженности из-за рубежа, организация автоматического обмена информацией между налоговыми администрациями разных стран.

Отметим, что пока существенных результатов нововведения по противодействию снижению налоговой базы и перенесению доходов не имеют, кроме того, высказываются опасения о возможном обратном эффекте - становится непривлекательной идея создания международных холдинговых компаний в России [9].

Одним из важнейших приоритетов российской налоговой политики является сохранение и развитие человеческого капитала. В рамках данного направления с 1 января 2015 г. в НК РФ введена новая глава «Налог на недвижимое имущество физических лиц». Закон основывается на введении новых принципов в налогообложении имущества физических лиц, направленных на более полный охват объектов налогообложения и обеспечение принципа справедливости в налогообложении в зависимости от условий проживания и реальной рыночной стоимости объектов налогообложения. Новый порядок налогообложения может вводиться субъектом РФ вплоть до 2020 г. Обязательным условием введения является утверждение результатов государст- 
венной оценки объектов капитального строительства. Аналогично стандартным вычетам по НДФЛ предусматриваются «жилищные» налоговые вычеты в размере стоимости установленной площади (мкв.) объекта (дом, квартира, комната). Размер ставок на жилые помещения - до 0,1\%.

Понятно, что новый подход к налогообложению имущества физических лиц вызывает тревогу у населения - правильно ли оценили их объект? Не станет ли уплачиваемая сумма налога непосильной для семейного бюджета? Следует отметить, что на переходный период субъектами РФ налоговые ставки установлены исходя из проведённых прогнозных расчетов ожидаемых величин налога, подлежащего к уплате по группам недвижимости, которые не допускают существенного увеличения налоговой нагрузки (за исключением дорогих объектов капитального строительства). Хотя, конечно, возможны отклонения и перекосы.

Также отметим, что с 2016 г. планируется полное освобождение доходов от продажи жилой недвижимости вне зависимости от сроков владения ею (более или менее трех лет) [10].

Следующим самостоятельным направлением налоговой политики РФ стало совершенствование налогового администрирования. Так, в соответствии с дорожной картой «Совершенствование налогового администрирования» [11] в 2015-2017 гг. будет продолжен комплекс мер по дальнейшему усовершенствованию налогового администрирования. В части нововведений особо следует выделить:

- реформирование концептуального подхода к организации контроля за налогоплательщиками, в том числе применение контрольных процедур воздействия налоговыми органами на налогоплательщика в соответствии с моделью его поведения: исполняет ли налогоплательщик все обязанности и является добросовестным; старается, но не всегда успешно; не хочет исполнять обязанности и применяет различные схемы уклонения от уплаты налогов; использует ненаблюдаемую экономику [12]; изменение процедуры отбора налогоплательщиков с максимальным исключением человеческого фактора; повышение результативности контрольных мероприятий и качества процедур досудебного рассмотрения налоговых споров;

- внедрение института «предварительного налогового разъяснения», что должно существенно уменьшить количество налоговых споров и судебных разбирательств. Предварительное налоговое разъяснение - это квалифицированный обоснованный ответ налогового органа на обращение налогоплательщика по правильности налогообложения той или иной хозяйственной операции. Таким образом, оно выдается на будущие операции и особо актуально, например, при согласовании налогоплательщиками контролируемых сделок в рамках контроля трансфертного ценообразования. Данный механизм должен повысить статус уже привычных налоговых разъяснений, регламентировать правоотношения и налоговые последствия и, вероятно, на первых этапах должен распространяться на крупные сделки;

- введение института «горизонтального налогового мониторинга», когда налоговый орган в режиме реального времени получает доступ к данным бухгалтерского и налогового учета налогоплательщика и может проверять и согласовывать правильность и своевременность отражения хозяйственных 
операций налогоплательщика, формирования налоговых баз и их отражения в отчетности. В случае расхождения мнения налогоплательщика с позицией налогового органа инициируется взаимосогласительная процедура на уровне центрального аппарата ФНС. При подаче заявления о налоговом мониторинге к данным налогоплательщикам не будут применяться иные формы налогового контроля (выездные и камеральные налоговые проверки). Понятно, что в этом случае снижаются налоговые риски бизнеса и формируется максимально возможная доверительная схема отношений фискальных органов с налогоплательщиками. Горизонтальный налоговый мониторинг реализовывался в 2012-2013 гг. в качестве пилотного проекта, например в ОАО «РусГидро», ОАО «ИНТЕР РАО ЕЭС», ОАО «Мобильные ТелеСистемы», «Эрнст энд Янг (СНГ) Б.В.», ОАО «Северсталь», «Интер РАО» [13]. В настоящее время данный механизм могут использовать крупнейшие налогоплательщики, стоимость активов которых составила за год более 3 млрд руб., суммарная доля доходов за предыдущий налоговый период была равна 3 млрд руб., а общая сумма налогов (ДС, налога на прибыль организаций, акцизов, НДПИ) превысила 300 млн руб. [14]. С 1 января 2016 г. воспользоваться горизонтальным мониторингом смогут консолидированные группы налогоплательщиков;

- упорядочивание статуса института налогового консультирования на основе принятия закона «О налоговом консультировании», позволяющего регламентировать деятельность налоговых консультантов: законодательно урегулировать порядок налогового консультирования, установить права и обязанности налоговых консультантов и пользователей их услуг, гарантии качества этих услуг, ответственность как конкретного налогового консультанта, так и их профессионального сообщества [15];

- введение полноценной версии и совершенствование функционала личного кабинета налогоплательщиков - юридических лиц; отметим, что с 1 июля 2015 г. вступает в силу закон, устанавливающий официальный статус интернет-сервиса «Личный кабинет налогоплательщика», позволяющий почти полностью избежать контакты налогоплательщиков с налоговыми органами: представлять налоговую отчетность в электронном виде (без фирмпосредников), контролировать расчеты в режиме on-line, получать в электронном виде документы от налоговых органов, производить уточнения, зачет или возврат и многое другое;

- введение личного кабинета налогоплательщиков - индивидуальных предпринимателей, особенностью которого станет своеобразный «ликбез» для данных субъектов малого бизнеса;

- расширение электронного документооборота между налогоплательщиками и налоговыми органами за счет введения возможности получения налогоплательщиками документов (актов сверок расчетов по налогам, сборам, пеням и штрафам, справок об отсутствии задолженности и иных документов по требованию налогоплательщика) от налогового органа по телекоммуникационным каналам с электронной подписью должностного лица налогового органа по требованию налогоплательщика;

- применение новой архитектуры администрирования НДС, основанной на электронном декларировании товарооборота (счетов-фактур); таким обра- 
зом, налогоплательщики теперь обязаны представлять декларацию по НДС в электронном виде с прикреплением к ней книги учета счетов-фактур также в электронном виде, что позволит налоговым органам в автоматическом режиме выявлять «налоговые разрывы».

В 2015 г. продолжается ранее начатое направление налоговой политики по стимулированию инвестиционной активности и обеспечению опережающего социально-экономического развития на Дальнем Востоке и в Восточной Сибири. Речь идет о налоговом стимулировании реализации региональных инвестиционных проектов на территориях Дальневосточного федерального округа, Забайкальского края, Республики Бурятия, Иркутской области с расширением этого режима на Республику Хакасия, Республику Тыва, Красноярский край, Крым и Севастополь.

На данных территориях должны быть созданы особые условия ведения предпринимательской деятельности для новых предприятий, в том числе пятилетние «каникулы» по налогу на прибыль организаций, НДПИ (за исключением нефти и газа), земельному налогу, налогу на имущество организаций. Предусматривается также введение преференций по страховым взносам во внебюджетные фонды, которые будут определены законодательством о государственном социальном страховании [16].

Предложенная мера действительно направлена на привлечение капитальных вложений и бизнеса, рассчитана на последующий бюджетный и социально-экономический эффект для территорий. Однако при этом приведет к дополнительному неравенству в инвестиционной привлекательности отдалённых территорий, например, Западной и Восточной Сибири.

В качестве новых мер по стимулированию предпринимательской активности и налоговому «оформлению» малым предпринимательством отношений с государством стало введение «налоговых каникул» для малого бизнеса в 2015-2018 гг. Налоговые каникулы могут вводиться региональными уровнями власти для впервые зарегистрированных индивидуальных предпринимателей, выбравших патентную систему налогообложения или упрощенную систему налогообложения и осуществляющих деятельность в производственной, социальной и научной сферах, в виде налоговой ставки в размере $0 \%$.

При этом субъектам РФ предоставлено вправо устанавливать ограничения на применение налоговой ставки в размере $0 \%$, в том числе в виде предельного размера доходов индивидуальных предпринимателей, количества наемных работников и иных показателей.

Планируется расширить и сферу применения патентной системы налогообложения, предложив её так называемым «самозанятым» гражданам. Предполагается, что самозанятые граждане будут становиться на учет в налоговом органе в качестве налогоплательщиков патентной системы налогообложения и в качестве индивидуальных предпринимателей на основании заявления на получение патента и сниматься с учета в качестве налогоплательщиков и индивидуальных предпринимателей по истечении срока действия этого патента.

Что касается оценки эффективности проводимой налоговой политики России, то она должна даваться по комплексу показателей, раскрывающих основные функции налоговой системы: фискальной эффективности, результативности регулирования социально-экономических процессов в обществе в 
соответствии с тактическими и стратегическими планами развития страны, эффективности налогового контроля в целом и его отдельных направлений, соответствия распределительных процессов федеративному устройству страны и проч.

Можно однозначно сказать, что фискальную функцию налоговые органы обеспечивают, активно совершенствуется механизм реализации контрольной функции, а вот регулирующая и распределительная функции нуждаются в концептуально-методической доработке, обосновании новых инструментов и их дальнейшем внедрении в налоговую систему РФ.

Итак, применяемые новые инициативы в налоговой политике страны в основном направлены на «точечное» улучшение методов и инструментов налоговой системы и постепенную корректировку результативности выполнения ею основных функций.

Мы согласны с позицией, что в условиях экономических неопределённостей нецелесообразно проводить кардинальные реформы налоговой системы. Но готовить и обосновывать их нужно. При этом прежде всего требуется решение по следующим основным моментам:

1) какое налогообложение будет преимущественно реализовываться в России - прямое или косвенное?

2) на что будет направлена налоговая нагрузка - на труд или капитал (и какой капитал или доходы будут более интенсивно облагаться)?

3) какие отрасли экономики (виды деятельности), территории получат льготы и иные преференции и на каких условиях?

4) какими методами обеспечивать реализацию принципов эффективности и справедливости в налоговой системе (чьи интересы считать приоритетными)?

5) будут ли корректироваться объёмы налоговых полномочий в отношении регионов и муниципальных образований и какими финансовобюджетными механизмами они будут сопровождаться?

6) какой «налоговый климат» будет установлен в российской налоговой юрисдикции для иностранного капитала? Кем выгоднее быть: резидентом или нерезидентом?

Все вышеперечисленное должно определить состав налогов, действующих на территории РФ, порядок формирования налоговых обязательств, состав и механизм предоставления налоговых льгот, уровень налоговой нагрузки и пределы её дифференциации в зависимости от масштабов бизнеса, видов и подвидов экономической деятельности, пределы изъятия дифференциальной ренты, распределение состава закреплённых и регулирующих налогов по уровням Федерации и объёма налоговых полномочий, структуру налоговых органов, объёмы и условия их финансирования.

Конечно, предложения по реформированию налоговой системы в научной литературе присутствуют (см., например, [17-20],) однако эти предложения обосновывают отдельные стороны обозначенных выше направлений, зачастую не воспринимаются правительством. Требуется единый комплексный подход, взаимоувязывающий все основновополагающие моменты, базирующиеся на современной методологии построения налоговых систем.

Таким образом, пора приступать к формированию принципиально новой 
налоговой политики и на её основе выстраивать налоговую систему России, соответствующую стратегическим целям развития страны и обеспечивающую выведение налогового инструментария в механизме государственного управления на принципиально иной уровень.

\section{Лuтература}

1. Пансков В.Г. Налоговые полномочия региональных органов власти и перспективы наполнения бюджетной системы // Налоговый маневр. 2014: взгляд бизнеса и власти. X Всероссийский налоговый форум. URL: http://www.tpprf.ru/ru/interaction/legislative/60812

2. Греков И.Е. О несостоятельности доводов сторонников плоской шкалы налога на доходы физических лиц // Управление общественными и экономическими системами. 2011. № 1. URL: http://umc.gu-unpk.ru/umc

3. О внесении изменений в отдельные законодательные акты РФ по вопросам обязательного пенсионного страхования [Электронный ресурс] : федер. закон Рос. Федерации от 3 декабря 2012 г. № 243-Ф3 // КонсультантПлюс: справ. правовая система. Версия Проф. Электрон. дан. М., 2015. Доступ из локальной сети Науч. б-ки Том. гос. ун-та.

4. О внесении изменений в часть вторую Налогового кодекса Российской Федерации и отдельные законодательные акты Российской Федерации [Электронный ресурс]: федер. закон Рос. Федерации от 24 ноября 2014 г. № 366-Ф3 // КонсультантПлюс: справ. правовая система. Версия Проф. Электрон. дан. М., 2015. Доступ из локальной сети Науч. б-ки Том. гос. ун-та.

5. O внесении изменений и дополнений в отдельные законодательные акты Российской Федерации в связи с совершенствованием принципов определения цен для целей налогообложения [Электронный ресурс]: федер. закон от 18 июля 2011 г. № 227-Ф3 // КонсультантПлюс: справ. правовая система. Версия Проф. Электрон. дан. М., 2015. Доступ из локальной сети Науч. б-ки Том. гос. ун-та.

6. Гринкевич Л.С., Олофинская Ю.П. Внедрение методики управления рисками контроля цен по сделкам в практическую деятельность российского бизнеса // Вестн. Том. гос. ун-та. Экономика. № 4 (28). Томск: Изд-во Том. ун-та, 2014. С. 87-94.

7. О внесении изменений в части первую и вторую Налогового кодекса Российской Федерации (в части налогообложения прибыли контролируемых иностранных компаний и доходов иностранных организаций) [Электронный ресурс]: федер. закон от 24 ноября 2014 г. № 376-Ф3 // КонсультантПлюс: справ. правовая система. Версия Проф. Электрон. дан. М., 2015. Доступ из локальной сети Науч. б-ки Том. гос. ун-та.

8. Основные направления налоговой политики РФ на 2015 год и на плановый период 20162017 годов (Одобрены Правительством Российской Федерации 1 июля 2014 года) // КонсультантПлюс: справ. правовая система. Версия Проф. Электрон. дан. М., 2015. Доступ из локальной сети Науч. б-ки Том. гос. ун-та.

9. Налоговая нагрузка на бизнес в 2014 году. Непростые налоговые решения: повысить, зафиксировать, понизить? // Налоговый маневр - 2014: взгляд бизнеса и власти. X Всероссийский налоговый форум. URL: http://www.tpprf.ru/ru/interaction/legislative/60812

10. О внесении изменений в части первую и вторую Налогового кодекса Российской Федерации [Электронный ресурс]: федер. закон от 29 ноября 2014 г. № 382-Ф3 // КонсультантПлюс: справ. правовая система. Версия Проф. Электрон. дан. М., 2015. Доступ из локальной сети Науч. б-ки Том. гос. ун-та.

11. Об утверждении плана мероприятий («дорожной карты») «Совершенствование налогового администрирования» [Электронный ресурс]: Распоряжение Правительства РФ от 10 февраля 2014 года № 162-р (в ред. от 03.12.14) // КонсультантПлюс: справ. правовая система. Версия Проф. Электрон. дан. М., 2015. Доступ из локальной сети Науч. б-ки Том. гос. ун-та.

12. Мишустин М.В. Основные направления налоговой политики России до 2017 года // Налоговый маневр - 2014: взгляд бизнеса и власти. X Всероссийский налоговый форум. URL: http://www.tpprf.ru/ru/interaction/legislative/60812

13. Мостовая И.Г. Налоговый мониторинг: новый уровень отношений между компаниями и налоговыми органами // Налогообложение, учет и отчетность в коммерческом банке. 2014. № 8. С. 49-54. 
14. О внесении изменений в часть первую Налогового кодекса РФ [Электронный ресурс]: федер. закон от 4 ноября 2014 г. № 348-Ф3 // КонсультантПлюс: справ. правовая система. Версия Проф. Электрон. дан. М., 2015. Доступ из локальной сети Науч. б-ки Том. гос. ун-та.

15. Бондаренко O.A. Налоговый консультант должен иметь комплексную подготовку обладать знаниями юриста и аудитора // Российский налоговый курьер. 2014. № 3. С. 4-7.

16. Лермонтов Ю. Основные направления налоговой политики на 2015-2017 годы // Российский бухгалтер. 2014. № 9. С. 10-23.

17. Пансков В.Г. О возможных направлениях налоговой политики // Финансы. 2012. № 5. C. $30-34$.

18. Гринкевич Л.С. Модернизация налоговой системы России на базе концепции бюджетно-налогового федерализма // Налоги и налогообложение: палитра современных проблем / И.А. Майбуров и др.; под ред. И.А. Майбурова, Ю.Б. Иванова. М.: ЮНИТИ-ДАНА, 2014. 375 с.

19. Экономика налоговых реформ / под ред. И.А. Майбурова, Ю.Б. Иванова, Л.Л. Тарангул. К.: Алерта, 2013. 432 с.

20. Налоговые реформы. Теория и практика / И.А. Майбуров [и др.] / под ред. И.А. Майбурова, Ю.Б. Иванова. М.: ЮНИТИ-ДАНА, 2013. 463 с.

Grinkevich Larisa S. Department of World Economy and Taxation, National Research Tomsk State University, Tomsk, Russia. E-mail: Nasty_saturn@mail.ru

"TAX MANEUVER", DEOFFSHORIZATION OF ECONOMY AND OTHER DIRECTIONS OF MODERN RUSSIAN TAX POLICY.

Keywords: Tax policy; Tax maneuver; Deoffshorization of economy; Improvement of tax administration.

The tax policy of the Russian Federation for 2015 and subsequent periods was developed under the urge to choose between the need to significantly increase tax revenues to the budget and avoid an increase in the tax burden on the economy.

As a result, the new tools of the tax system were adopted, allowing supporting the public sector through better tax control and administration and reasonable redistribution of the tax burden between the sectors of the economy, legal entities and individuals.

The major innovations of the Russian tax policy are:

- "tax maneuver" is a set of changes to the tax system, including: expansion of the list of excisable goods; the tax increase on dividend income from $9 \%$ to $13 \%$ for organizations and individuals; indexation of water tax; gradual reduction of export duties on oil and petroleum products with a simultaneous increase in mining extraction tax (oil and gas condensate);

- measures to counter the reduction in the tax base and the transfer of income, including: taxation of undistributed profits of controlled foreign companies, elimination of tax advantages for foreign companies; countering tax evasion by beneficial owners; improvement of the practices in the transfer legislation;

- a new procedure for taxation of real estate of individuals; Far East;

- a set of tax measures to increase the investment attractiveness of regions of East Siberia and the

- measures to further improve tax administration mechanisms: improvement of functionality of taxpayers' personal account for legal entities; the establishment of the taxpayers' personal account for individual entrepreneurs; the improvement of electronic document flow between taxpayers and tax authorities; the introduction of horizontal tax monitoring; the introduction of the institute of advance tax ruling; the development of the law on tax consulting; the change of conceptual approaches to tax audits; the use of the new VAT administration architecture; expansion of forms and mechanisms of international cooperation;

- promotion of investment and ensuring the outpacing social and economic development in the Far East, several regions of Eastern Siberia, and the Crimea;

- an introduction of "tax holidays" for small business - individual entrepreneurs and selfemployed and other.

The assessment of the tax policy implemented by the Russian Federation allows to conclude that the new tax initiatives being introduced are mainly focused at "targeted" improvement of methods and instruments of the tax system.

It is time to develop a brand new tax policy based on an advanced methodology of tax systems construction, consistent with the country's strategic development objectives and clearly defining the set 
of the most significant issues in the tax system: who and what is taxed, what proportions to choose when distributing tax burden and revenues, who and under what conditions receives tax exemptions, whose interests are of higher priority at this stage of development of the country and other.

\section{References}

1. Panskov V.G. Nalogovyye polnomochiya regional'nykh organov vlasti i perspektivy napolneniya byudzhetnoy sistemy [Tax responsibilities of regional authorities and the prospects of the budget system filling]. Nalogovyy manevr - 2014: vzglyad biznesa $i$ vlasti. Available at: http://www.tpprf.ru/ru/interaction/legislative/60812 (accessed 20 January 2015).

2. Grekov I.E. O nesostoyatel'nosti dovodov storonnikov ploskoy shkaly naloga na dokhody fizicheskikh lits [On the inconsistency of arguments of the supporters of the flat personal income tax]. Upravleniye obshchestvennymi i ekonomicheskimi sistemami, 2011, no. 1. Available at: http://umc.guunpk.ru/umc (accessed 20 January 2015).

3. RF Federal Law "On Amendments to Certain Legislative Acts of the Russian Federation on the Issues of Compulsory Pension Insurance" of December 3, 2012, N 243-FZ. Available at: http://www.consultant.ru/ (accessed 20 January 2015). (In Russian).

4. RF Federal Law "On Amendments to Part Two of the Tax Code of the Russian Federation and Certain Legislative Acts of the Russian Federation" of November 24, 2014, N 366-FZ. Available at: http://www.consultant.ru/ (accessed 20 January 2015). (In Russian).

5. RF Federal Law "On Amendments and Additions to Certain Legislative Acts of the Russian Federation in connection with the Improvement of Pricing Principles for Tax Purposes" of July 18, 2011, N 227-FZ. Available at: http://www.consultant.ru/ (accessed 20 January 2015). (In Russian).

6. Grinkevich L.S., Olofinskaya Yu.P. Vnedreniye metodiki upravleniya riskami kontrolya tsen po sdelkam v prakticheskuyu deyatel'nost' rossiyskogo biznesa [Implementation of methodology of price risk management on transactions into the Russian business practice]. Vestnik Tomskogo gosudarstvennogo universiteta. Ekonomika-Tomsk State University Journal of Economics, 2014, no. 4(28), pp. 87-94.

7. . RF Federal Law "On the Introduction of Amendments to Parts One and Two of the Tax Code of the Russian Federation (Regarding Taxation of the Profits of Controlled Foreign Companies and Income of Foreign Organizations)" of November 24, 2014, N 376-FZ. Available at: http://www.consultant.ru/ (accessed 20 January 2015). (In Russian).

8. Government of the Russian Federation. "The Main Directions of Tax Policy of the Russian Federation for 2015 and the 2016-2017 planning period" of July 1, 2014. Available at: http://www.consultant.ru/ (accessed 15 January 2015). (In Russian).

9. Nalogovaya nagruzka na biznes v 2014 godu. Neprostyye nalogovyye resheniya: povysit', zafiksirovat', ponizit'? [The tax burden on business in 2014. Complicated tax solutions: raise, fix, reduce?]. Nalogovyy manevr - 2014: vzglyad biznesa $i$ vlasti. Available at: http://www.tpprf.ru/ru/interaction/legislative/60812 (accessed 20 January 2015).

10. . RF Federal Law "On the Introduction of Amendments to Parts One and Two of the Tax Code of the Russian Federation" of November 29, 2014, N 382-FZ. Available at: http://www. consultant.ru/ (accessed 15 January 2015). (In Russian).

11. RF Government Edict "On Approval of the Activity Plan of "The Roadmap" "Improving Tax Administration" of February 10, 2014 N 162-r. Available at: http://www.consultant.ru/ (accessed 15 January 2015). (In Russian).

12. Mishustin M.V. Osnovnyye napravleniya nalogovoy politiki Rossii do 2017 goda [The main directions of tax policy of Russia up to 2017]. Nalogovyy manevr - 2014: vzglyad biznesa $i$ vlasti. Available at: http://www.tpprf.ru/ru/interaction/legislative/60812 (accessed 20 January 2015).

13. Mostovaya I.G. Nalogovyy monitoring: novyy uroven' otnosheniy mezhdu kompaniyami i nalogovymi organami [Tax monitoring: a new level of relations between companies and tax authorities]. Nalogooblozheniye, uchet i otchetnost' v kommercheskom banke, 2014, no. 8, pp. 49-54.

14. RF Federal Law "On the Introduction of Amendments to Part One of the Tax Code of the Russian Federation" of November 4, 2014, N 348-FZ. Available at: http://www.consultant.ru/ (accessed 15 January 2015). (In Russian).

15. Bondarenko O.A. Nalogovyy konsul'tant dolzhen imet' kompleksnuyu podgotovku obladat' znaniyami yurista i auditora [A tax consultant should have comprehensive qualifications possess knowledge of a lawyer and auditor]. Rossiyskiy nalogovyy kur'yer, 2014, no. 3, pp. 4-7. 
16. Lermontov Yu. Osnovnyye napravleniya nalogovoy politiki na 2015-2017 gody [The main directions of tax policy for the 2015-2017 period]. Rossiyskiy bukhgalter, 2014, no. 9, pp. 10-23.

17. Panskov V.G. O vozmozhnykh napravleniyakh nalogovoy politiki [On the issue of possible tax policy directions]. Finansy, 2012, no. 5, pp. 30-34.

18. Grinkevich L.S. Modernizatsiya nalogovoy sistemy Rossii na baze kontseptsii byudzhetnonalogovogo federalizma [Modernization of the Russian tax system on the basis of fiscal federalism concept]. In: I.A. Mayburov et al (eds.). Nalogi i nalogooblozheniye: palitra sovremennykh problem. Moscow, YUNITI-DANA Publ., 2014. 375 p.

19. Mayburov I.A., Ivanov Yu.B., Tarangul L.L. (Eds.) Ekonomika nalogovykh reform [The economics of tax reforms]. Kiev, Alerta Publ, 2013. 432 p.

20. Mayburov I.A., Ivanov Yu.B. et al (eds.). Nalogovyye reformy. Teoriya i praktika [Tax reform. Theory and practice]. Moscow, UNITY-DANA Publ., 2013. 463 p.

Поступила в редакцию DD.MM.2015

Received March DD, 2015

\section{For referencing:}

Grinkevich L.S. "Nalogovyy manevr", deoffshorizatsiya ekonomiki i drugiye napravleniya sovremennoy nalogovoy politiki rossii ["Tax maneuver", deoffshorization of economy and other directions of modern Russian tax policy]. Vestnik Tomskogo gosudarstvennogo universiteta. Ekonomika - Tomsk State University Journal of Economics, 2015, no. 1 (29), pp. 138-150. 